\title{
Research on Dynamic Analysis of Financial Performance of Listed Companies on GEM
}

\author{
Zhonglin Sui ${ }^{1, \text { a }}$ \\ ${ }^{1}$ College of Business Administration, Jilin Engineering Normal University, Changchun City, China \\ a1164849905@qq.com
}

\begin{abstract}
Keywords: Financial performance; Efficacy coefficient method; Growth Enterprise Market (GEM); Dynamic Analysis
\end{abstract}

\begin{abstract}
The GEM has worked officially for seven years on the Shenzhen stock exchange since company listed on the Gem on October 2009. Based on this, the financial performance of companies listed on GEM of a comprehensive evaluation. Firstly, the concept and characteristics of GEM listed companies were reviewed, and our GEM listed companies 'financial performance evaluation method described and selection; secondly, binding is used herein efficacy coefficient method, Construction of GEM listed companies' financial performance evaluation index system, and then were clear evaluation criteria, scoring and evaluation results; Third, with the first batch of GEM listed 28 companies 2009 to 2015 financial statements as an object of study, its financial health benefits, assets operating capacity situation, compensation debt capacity situation and the capacity situation developing financial performance of dynamic analysis and evaluation of the results showed that the GEM nearly seven years financial performance declined; Finally, based on our GEM listed company's specific circumstances, the analysis of the results, the GEM listed companies to improve business performance, strengthen supervision and inspection, optimization suggestions investor structure.
\end{abstract}

\section{Introduction}

The market mechanism and the regulatory system are constantly improved since the Gem starts up on the Shenzhen stock exchange in October 2009 .However, the GEM market in development stage still exist many problems, for example not stable performance, Higher Price- to- earnings ratio, market bubble and so on [1]. This makes the gem deviate from the goal of optimizing the allocation of resources, it donot provide full services for the development of enterprises as the financing channels. Its financial performance has increasingly aroused widespread concern of market participants and the community. So the dynamic evaluation of financial performance is of great significance.

\section{Evaluation Theory of Financial Performance of Listed Companies on GEM}

The Concept and Characteristics of GEM. The Gem market, also known as growth type stock market, Refers to the market besides the main board Market. It special help small and medium sized enterprises unlisted temporarily, or innovative companies, In particular, high-tech companies to raise capital and capital operation [1]. The development of gem in China is not only to provide convenient financing channels for small and medium enterprises but Also to create a normal exit mechanism for the venture capital. At the same time, it is also an important means to adjust the industrial structure and promote economic reform in China.

The Choice of Evaluation Method for Financial Performance. Along with the advance of enterprise's management level, financial performance analysis and evaluation method has been continually improved. At present, the extensive used methods include dupont financial analysis system, wall scoring system, EVA (Economic Value Added) evaluation system, the balanced scorecard system, efficacy coefficient method, etc. [2]. According to comparison of the different financial performance evaluation system, as shown in Table 1: 
Table 1 Comparative conclusions of evaluation method of financial performance

\begin{tabular}{l|l}
\hline Evaluation method & comparative conclusions \\
\hline $\begin{array}{l}\text { Dupont financial } \\
\text { analysis system }\end{array}$ & Only consider financial index, can not fully reflect the enterprise strength \\
\hline Wall scoring system & $\begin{array}{l}\text { The selection of indicators and the determination of weight is considerable } \\
\text { subjective, it need to be proved in theory. }\end{array}$ \\
\hline $\begin{array}{l}\text { Economic Value } \\
\text { Added evaluation } \\
\text { system }\end{array}$ & $\begin{array}{l}\text { The cost of capital are difficult to determine, and manipulation will be more } \\
\text { difficult to be measure }\end{array}$ \\
\hline $\begin{array}{l}\text { The balanced } \\
\text { scorecard system }\end{array}$ & $\begin{array}{l}\text { Non-financial indicators are difficult to quantify, with very strong } \\
\text { subjectivity, difficult to compare between different enterprises. }\end{array}$ \\
\hline
\end{tabular}

Efficacy coefficient method reduces the gap between the indicators and integrates the different factors of enterprise performance, so it can reflect the comprehensive situation of enterprise performance. Second, it is suitable for conditions and complexity of Chinese business, because the efficacy coefficient method meets the requirements of the multi-factor and multi-level. The efficacy coefficient method was applied and continuously revised by the ministry of finance and other five ministries and commissions since 2002. Therefore, we choose efficacy coefficient method as the dynamic evaluation method for enterprise financial performance.

\section{Construction of Financial Performance Evaluation Methods of Listed Companies on GEM}

Construction of Financial Performance Evaluation Index System. It analyzed and evaluated dynamically the first 28 companies listed on the gem in Shenzhen stock exchange ${ }^{1}$. We chose the 28 companies as the sample in consideration of its maturity and integrity and accuracy to express the result of dynamic analysis, because the first batch of listed companies developed and grown for seven years, relatively maturity compared with other listed companies.

According to "Operating rules for the evaluation of enterprise performance" issued by China's five ministries jointly in 2002, referring to "analysis and evaluation of financial performance of companies listed on GEM" written by Guohong Zhen and Zhonglin Sui [3], considering the data available and the feasibility of the operation method and the guidance of right $t$ goal, dynamic analysis index system includes basic index, a total of 8 indicators . At the same time, in order to maintain comparability of dynamic analysis, the weight given to the data by the indicators are unchanged in seven years, the concrete indicators and weight as shown in Table 2.

Table 2 Basic indexes in GEM and their weights ${ }^{2}$

\begin{tabular}{|c|c|c|c|}
\hline Content & Weight & Basic index & Weight \\
\hline \multirow{2}{*}{ Financial benefit } & \multirow{2}{*}{38} & return on net assets & 25 \\
\hline & & rate of return on total assets & 13 \\
\hline \multirow{2}{*}{ Asset operation } & \multirow{2}{*}{18} & turnover of total capital & 9 \\
\hline & & turnover of current assets & 9 \\
\hline \multirow{2}{*}{ Debt paying ability } & \multirow{2}{*}{20} & asset-liability ratio & 12 \\
\hline & & interest coverage & 8 \\
\hline \multirow{2}{*}{ Growth capacity } & \multirow{2}{*}{24} & Sales Growth Rate & 12 \\
\hline & & rate of capital accumulation & 12 \\
\hline Total & 100 & & 100 \\
\hline
\end{tabular}

\footnotetext{
${ }^{1}$ The data sources: the financial data involved in the article are from annual bulletin in information disclosure cninf Designated by the China Securities Regulatory Commission (www.cninfo.com.cn) and Website of the Shenzhen Stock Exchange (www.szse.cn).

${ }^{2}$ Ministry of finance of China. Fiscal series [2002] fifth, Performance evaluation of enterprise operating rules (Revised)[S]:1-10.
} 
The Determination of Evaluation Standard of Financial Performance Index. This paper is based on the report data resulted from the first companies listed on the gem in 2009 in order to maintain the objectivity and consistency of dynamic evaluation, by means of cloud computing platform, the progressive average method is adopted, finally determines standard numerical of the evaluation for basic financial indicators through statistical calculation after eliminating extreme numerical, as shown in Table 3:

Table 3 Standard value of basic indexes in $\mathrm{GEM}^{3}$

\begin{tabular}{l|l|l|l|l|l}
\hline \multicolumn{1}{c}{ Standard coefficient } & Poor & lower & commonly & fine & excellent \\
\cline { 2 - 6 } \multicolumn{1}{c}{ Index } & 0.2 & 0.4 & 0.6 & 0.8 & 1.0 \\
\hline Return on net assets (\%) & 10.45 & 12.13 & 14.17 & 17.33 & 23.82 \\
\hline rate of return on total assets (\%) & 9.62 & 11.15 & 14.03 & 16.53 & 21.80 \\
\hline turnover of total capital (times) & 0.39 & 0.47 & 0.58 & 0.69 & 0.76 \\
\hline turnover of current assets (times) & 0.49 & 0.55 & 0.69 & 0.85 & 0.94 \\
\hline asset-liability ratio (\%) & 5.88 & 8.42 & 14.20 & 23.12 & 35.16 \\
\hline interest coverage & 19.84 & 33.47 & 101.98 & 278.13 & 552.44 \\
\hline Sales Growth Rate (\%) & 12.56 & 21.24 & 34.18 & 57.47 & 114.95 \\
\hline rate of capital accumulation (\%) & 234.07 & 298.21 & 430.18 & 582.45 & 766.85 \\
\hline
\end{tabular}

The Determination of the Score and Results of Financial Performance Evaluation. On the basis of efficacy coefficient Scoring method, the cloud computing platform is used to calculate each index actual score, calculation formula are shown in Table 4 as below:

Table 4 The scoring formula of the basic indexes

The efficiency coefficient $=$ (the actual value - the file standard value $) /($ the standard value - the file standard value)

The file based score $=$ index weight $*$ standard coefficient of the file

The grade based score $=$ index weight $*$ the grade standard coefficient

Adjust points $=$ the efficiency coefficient $* \quad$ (the grade based score - the file based score)

Single index score $=$ The file based score + adjust points

Total score of basic indicators $=\sum$ Single basic index score

It needs to calculate index analysis coefficient of every part after index evaluation scores of this part is calculated, namely the ratio of evaluation scores and respective weight of the four parts of evaluation content.

The scores specified by "the performance evaluation of enterprise operating conditions (revised)" is the limit of qualification determining level types in this paper. The types that specific financial performance evaluation scores determine are shown in Table 5, as below:

\footnotetext{
${ }^{3}$ When the denominator is 0 or negative, rate of return on net assets and rate of capital accumulation score of 0 ; When the denominator is 0 , if the profit index is positive, the interest earned ratio is out, if the profit is 0 or negative, is the interest earned ratio is 0 .
} 
Table 5 Genus decision of score results through financial performance evaluation [4]

\begin{tabular}{|c|c|c|}
\hline Score & Type & Level \\
\hline $95-100$ & \multirow{3}{*}{ excellent (A) } & $\mathrm{A}++$ \\
\hline $90-95$ & & $\mathrm{~A}+$ \\
\hline $85-90$ & & $\mathrm{~A}$ \\
\hline $80-85$ & \multirow{3}{*}{ fine (B) } & $\mathrm{B}+$ \\
\hline $75-80$ & & $\mathrm{~B}$ \\
\hline $70-75$ & & B- \\
\hline $60-70$ & \multirow{2}{*}{ secondary (C) } & $\mathrm{C}$ \\
\hline $50-60$ & & $\mathrm{C}-$ \\
\hline $40-50$ & lower (D) & $\mathrm{D}$ \\
\hline $0-40$ & poor $(E)$ & $\mathrm{E}$ \\
\hline
\end{tabular}

Dynamic Analysis of Financial Performance of Listed Companies on GEM in Cloud Computing Platform

The Calculation of Financial Performance Indicators. On the basis of annual report during 2009-2015 of companies listed, actual index and correction index see Table 6.

Table 6 Basic index value of listed companies on GEM from 2009 to 2015

\begin{tabular}{|c|c|c|c|c|c|c|c|}
\hline Year & 2009 & 2010 & 2011 & 2012 & 2013 & 2014 & 2015 \\
\hline \multicolumn{8}{|l|}{ Financial benefit } \\
\hline Return on net assets (\%) & 0.14 & 0.10 & 0.11 & 0.10 & 0.09 & 0.08 & 0.10 \\
\hline $\begin{array}{l}\text { rate of return on total assets } \\
(\%)\end{array}$ & 0.14 & 0.10 & 0.10 & 0.11 & 0.10 & 0.10 & 0.09 \\
\hline \multicolumn{8}{|l|}{ Asset operation } \\
\hline turnover of total capital (times) & 0.65 & 0.50 & 0.57 & 0.58 & 0.64 & 0.64 & 0.60 \\
\hline $\begin{array}{c}\text { turnover of current assets } \\
\text { (times) }\end{array}$ & 0.78 & 0.61 & 0.76 & 1.72 & 0.98 & 1.05 & 1.07 \\
\hline \multicolumn{8}{|l|}{ Debt paying ability } \\
\hline asset-liability ratio $(\%)$ & 0.14 & 0.19 & 0.23 & 0.26 & 0.30 & 0.34 & 0.39 \\
\hline interest coverage & 4799.06 & 1612.69 & 473.54 & 735.87 & 168.63 & 626.93 & 148.06 \\
\hline \multicolumn{8}{|l|}{ Growth capacity } \\
\hline Sales Growth Rate（\%) & 0.34 & 0.32 & 0.37 & 0.28 & 0.28 & 0.38 & 0.37 \\
\hline $\begin{array}{l}\text { rate of capital accumulation } \\
(\%)\end{array}$ & 4.30 & 0.08 & 0.09 & 0.08 & 0.10 & 0.16 & 0.26 \\
\hline
\end{tabular}

Dynamic analysis and evaluation of individual financial performance. The weighting of financial efficiency position is 38 , the analysis coefficient is 0.25 , it means that the financial efficiency condition of companies listed on the gem was poor in China in 2015. According to seven years` data, we can make discount figure of financial efficiency position, as shown in Fig. 1: 


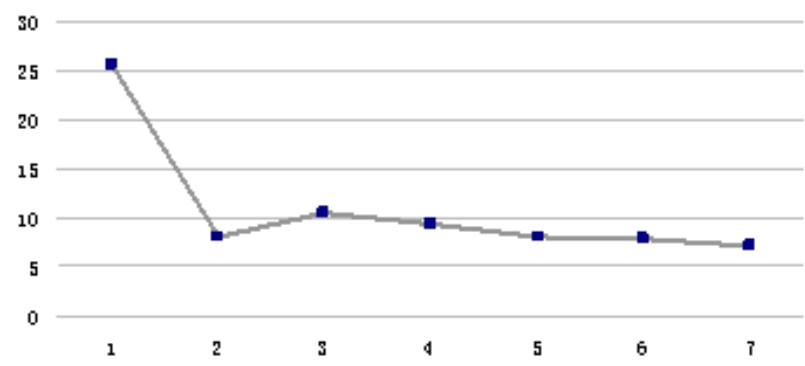

Figure 1. Financial efficiency score of Listed Companies on GEM in China from 2009 to 2015

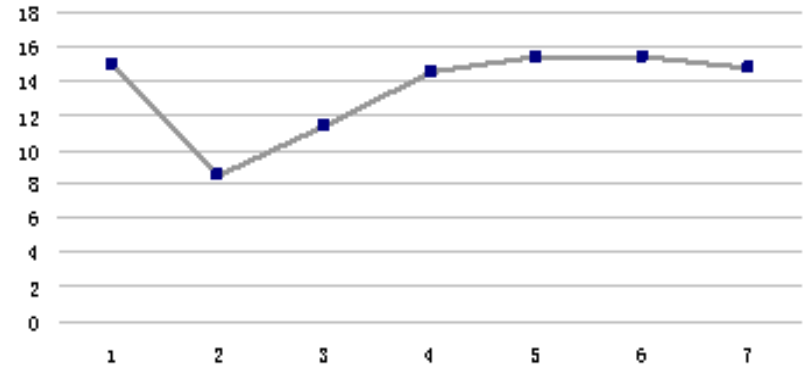

Figure 2. Asset operation score of Listed Companies on GEM in China from 2009 to 2015

We can clearly find that the overall condition of financial efficiency is steady but on the low side in addition to 2009 in Table 6, it appeared small rise in 2011 and 2014, but falled off a cliff in 2015, the ability that the total assets and free capital of enterprise earn profits is not high. The performance ability all have not yet reached the medium level, they drop to $0.31 \%, 0.39 \%$. Respectively for their profit rate of main business and surplus cash cover and ratio of profits to cost.

The weight in assets operating conditions section is 18, according to the adjusted scores of asset operating conditions in the Table 6 , the score is 14.80 , analysis coefficient is 0.66 , according to the conclusion, assets operation condition are shown in Fig. 2 below:

The Fig. 2 shows that the assets operation condition of the companies the first listed on the gem in China in 2010, showed a sharp decline, then presents a rising tendency, it were slipping as turning point in 2014. The total asset turnover among the basic indicators is relatively stable, and a $0.05 \%$ slight fluctuation shows that the operating efficiency that the company use its assets maintains in a general medium level; And although the current asset turnover ratio in the three years maintained in the medium level, a big rebound appeared as a turning point in 2012, however, the following three annual presented good momentum. From the highest point in 2012 to the point in 2015, a drop of $0.65 \%$, it demonstrates that the use of liquid assets is gradually improved.

The weighting of Solvency is 20, the scores is 17.22 for the first batch of companies listed on the gem in 2015, analysis coefficient is 0.28. The debt index scores are shown in Fig. 3 for the first batch of companies listed on the gem in China from 2009 to 2015.

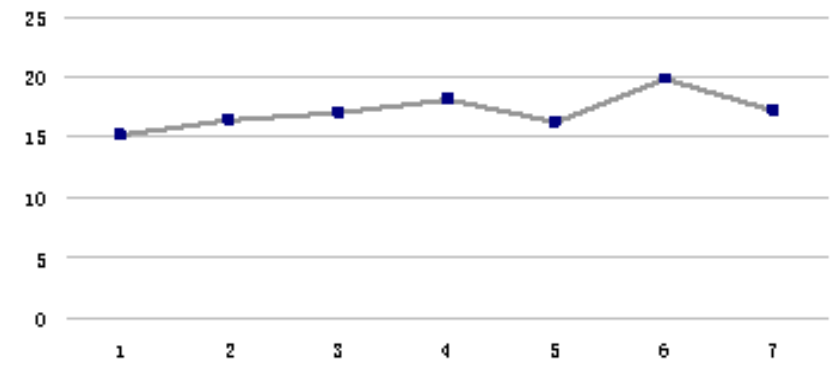

Figure 3. Debt paying ability score of Listed Companies on GEM in China from 2009 to 2015

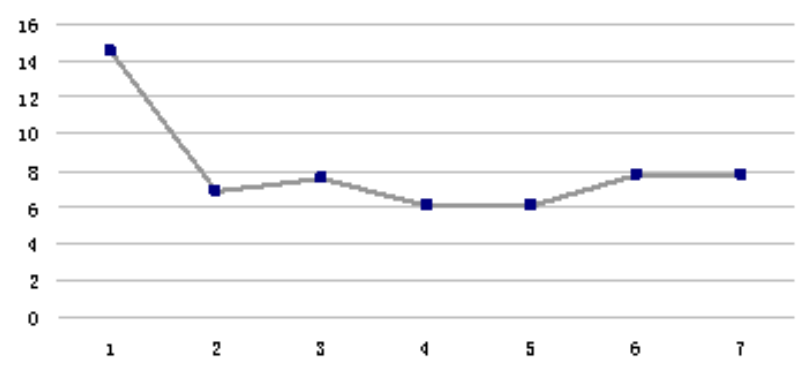

Figure 4. Growth capacity score of Listed Companies on GEM in China from 2009 to 2015

Fig. 3 shows that the solvency of the first batch of companies listed on the gem in our country showed a declining trend, but it showed the rebound trend at present. Although the asset-liability ratio in basic indicators present gradually rising trend, The range of the rise is up to $0.25 \%$, but it always keep within a reasonable range; the times of interest earned is affected by enterprise scale, it lead to instability of debt and interest, The extent of its fluctuations are big in the whole process, it reduced from 4799.06 in 2009 to 148.06 in 2015, annual performance ability are relatively good in addition to the 2013, 2015, weaker compared with the former performance. 
The weighting of enterprise development ability is 24 . The scores of development ability of the first batch of companies listed on the gem in 2015 is 7.73, analysis coefficient is 0.32 . We can determine the scores of development ability through calculation, as shown in Fig. 3 and Fig. 4.

According to Fig. 3 and Fig. 4, you can see that development capacity of the first batch of companies listed on the gem from 2009 to 2015 declined dramatically since 2010. The sales growth rate maintains a $0.03 \%$ rise in the medium level, also showed a rebound momentum in 2015. The sales growth of Baode Co.LTD. in 2015 is fastest up to $266.69 \%$.The three years average sales growing rate of yinjiang Co.LTD is $1.52 \%$. And capital accumulation rate in adjustment indexes fall, decline of $4.04 \%$ respectively.

Comprehensive Dynamic Analysis and Evaluation of Financial Performance. Comprehensive score of GEM listed companies by cloud computing changes as shown in Table 7:

Table 7 Comprehensive scores of Listed Companies on GEM from 2009 to 2015

\begin{tabular}{llllllll}
\hline Year & 2009 & 2010 & 2011 & 2012 & 2013 & 2014 & 2015 \\
\hline Basic index score & 63.91 & 39.95 & 46.52 & 48.13 & 45.90 & 51.10 & 46.88 \\
\hline
\end{tabular}

According to the above evaluation criteria, the comprehensive scores of financial performance of the first companies listed on the gem classify as grade type nearly seven years, as shown in Table 8:

Table 8 The type of the comprehensive score from 2009 to 2015

\begin{tabular}{cccccccc}
\hline Year & 2009 & 2010 & 2011 & 2012 & 2013 & 2014 & 2015 \\
\hline Type & secondary & poor & lower & poor & poor & poor & poor \\
Grade & C- & E & D & E & E & E & E \\
\hline
\end{tabular}

The results show that overall financial performance of the companies listed on the gem is at the level of low and decline slowly. The score of the basic financial performance evaluation index of the first listed companies on the gem in 2015 is 46.88 points, up to the lowest newly. According to the single dynamic analysis, it illustrates that financial performance level of the first batch of companies listed on the gem in our country were poor in the aspects of financial efficiency, solvency and development capacity conditions in addition to the capital operating conditions can be reached in general level. The big decline and poor performance indicators mainly include: the accounts receivable turnover ratio decreased by $21.34 \%$, the cash flow ratio decreased by $0.88 \%$ and the three years average capital growth rate decreased by $0.77 \%$. And it lead to the poor overall financial performance rating of the first batch of companies listed on the gem in our country.

\section{Dynamic Evaluation Conclusion of Financial Performance of Listed Companies on GEM}

Overall Operating Performance is weak. Through comprehensive analysis and evaluation for the first listed company on the gem, I think that overall financial performance level of companies listed on the gem is smooth, but is at a lower level. Theirs financial condition and the ability to repay its debt and growth ability for Sunny logistics, Jinya technology, baode Co., LTD. need to improve. The cause result in this is mainly from the reductions of the net cash flow, combining with the not sound enterprise's credit system. The increasing accounts receivable lead to the decrease of the solvency in daily business activities. Furthermore, negative growth of net capital appears, profitability and the ability of capital preservation are Severely affected.

Supervision mechanism is weak. From the perspective of corporate risk, the implementation standards of GEM in the approval of the listing is not strict enough or that the standard is too low, making a large number of GEM companies repeat listed with face-changing performance. With the growth of companies listed on GEM is not enough, in order to have been listed on the report whitewash 
or using patent together and after listing can bring benefits to the company, and thus can not show high growth, and increase the operation risk of the enterprise's own business risk and the whole market.

\section{References}

[1] Y.F. Wang: Study on the growth of the Companies on the GEM (MS., Southwestern University of Finance and Economics, China 2011), p.15-17.

[2] Y. Wang: The Financial Performance Evaluation of the GEM Listed Corporation in China (MS., Jiangxi Normal University, China 2013), p. 15-17.

[3] G.H. Zhen and Z.L. Sui: Communication of Finance and Accounting, Vol. 31 (2012) No.2, p.83-86+161.

[4] Ministry of finance of China. Fiscal series [2002] fifth, Performance evaluation of enterprise operating rules (Revised)[S]:1-10. 